\title{
LANGUAGE LEARNING STRATEGIES FROM THE PERSPECTIVE OF UNDERGRADUATES IN A PRIVATE ENGINEERING TECHNOLOGY UNIVERSITY IN JOHOR
}

\author{
Latipah Nordin ${ }^{1}$, Noor Zainab Abdul Razak ${ }^{2}$, Rahimah Kassim ${ }^{3}$ \\ ${ }_{1}^{1}$ Student Development Section, UniKL MITEC, Johor Bahru, Johor, Malaysia \\ ${ }^{2}$ Language Academy, Universiti Teknologi Malaysia, Johor Bahru, Johor, Malaysia ${ }^{3}$ Technical Foundation Section, UniKL MITEC, Johor Bahru, Johor, \\ Malaysia \\ *Corresponding Author Email: latipah@unikl.edu.mv, noorzainab@utm.mv, rahimahk@unikl.edu.mv
}

This is an open access article distributed under the Creative Commons Attribution License, which permits unrestricted use, distribution, and reproduction in any medium, provided the original work is properly cited

\section{ARTICLE DETAILS}

\section{Article History:}

Received 01 March 2019 Accepted 03 April 2019 Available online 08 April 2019

\section{ABSTRACT}

\begin{abstract}
Language learning strategies play a prominent role in second language learning as the information on students' preferred learning strategies may guide lecturers to select suitable teaching and learning activities. Hence, the objective of this study is to find out preferred language learning strategies employed by the students of engineering technology at UniKL MITEC, a private university in Johor Bahru offering engineering technology programs. A total of 146 students involved in this study and they were from semester 2 and semester 3 students enrolling in an English subject. Nevertheless, the respondents from semester 1 were not involved in this study since they were very new to the environment at the university. In order to determine students' preferred language learning strategies, Strategy Inventory of Learning Strategies (SILL) was employed. The questionnaire which consists of 50 items was provided in bilingual to ensure the clarity of every statement and to ensure the respondents to answer the questionnaire sincerely without guessing the meaning of certain words or statements. For data analysis, the findings were analysed statistically according to mean and standard deviation. Based on the analysis, it was found that the most preferred learning strategy is metacognitive strategies, followed by cognitive and compensation strategies, while the least preferred strategy is affective strategy. Thus, it shows that the engineering technology students employed less memory strategy. They prefer to manage their learning by making proper planning, monitoring and evaluating their learning. Thus, based on the findings of this study, lecturers are able to determine suitable activities which are more towards metacognitive strategies and followed by other strategies as to ensure the student will be exposed to various strategies.
\end{abstract}

\section{KEYWORDS}

Language Learning Strategies, Second Language Learning, Engineering Technology, SILL, Direct Learning Strategies, Indirect Learning Strategies

\section{INTRODUCTION}

Universiti Kuala Lumpur as higher learning institute focusing on engineering technology uses English as the medium of instruction since English is the language of technology. At the same time, using English as medium of instruction aims to equip students with good communication skills for them to secure a job locally or internationally. A researcher also commented that to be employed by multinational companies, students should have good language communication skills for English allows easyaccess to English-speaking societies and also developed countries [1]. Private universities like UniKL realized the importance of English for better future of students [2]. However, students of UniKL were rated as average language user by potential employers and this portrays that language proficiency is still the issue [3]. A group of researchers expressed their concern on having students with low language proficiency which will affect their overall academic performance since English is used in all subjects for certain higher learning institutes [4]. In addition, numerous studies have found that students with low language proficiency have difficulty to excel in their academic [5-7]. Thus, insufficient students' language proficiency in English still provides opportunities for researchers to look into the issue from the perspective of language learning strategies among the students of engineering technology. A researcher has also highlighted that it is important for lecturers to know students' preferred language learning strategies since learning strategies are capable to be taught [8].

\section{LITERATURE REVIEW}

Language learning strategy is among the four Individual Differences factors which have received special attention in second language research [9]. A researcher also claims that it is important to know about learning strategies since it can motivate learners to learn and to have more effective learning process [10]. In addition, other researchers recommended the relevancy of learning strategies toward language learning strategies [11,12]. It is also seconded by several researchers where the way the student completed the task makes them better learner [13-17]. Thus, these show that it is important to find out language 
learning strategies employ by learners in their learning process. A previous scholar has reviewed the studies on learning strategies conducted from 1970s up to 2009 [18]. In 1970s studies on learning strategies were focusing more on cognitive psychology, but the later part focused on the differences of learning strategies according to its category. It was followed with studies on learning strategies employed by successful learners in 1980s, and in 1990s researchers focused more on the factors which influence learners in selecting learning strategies that work best to them. Nonetheless, according to a researcher, categories of language learning strategies are still the main focus among researchers and language learning strategy is also one of the main elements in determining the success of language acquisition and achievement [19].

\subsection{Definitions of language learning strategies}

There are diversities of definitions on learning strategies where each theory approaches from different perspectives. A previous researcher perceives language learning strategies as behavior or steps taken by the learner in learning language [20,21]. However, another researcher state that learning strategies are precise thinking and communication process used by learners in order for them to acquire the language [22,23]. It shows that learners involve cognitive before selecting specific strategies according to the task given to them. A recent scholar also highlighted the definition which pro to behavior or specific actions taken in order to solve difficult task [24]. Meanwhile, language learning strategies can also be plan or action or even both for learners to take as a way for them to develop their language proficiency [25]. The definition provides by Mohamed Amin covers both behavior and cognitive aspects.

Apart of that, learning strategies are also considered as learning skills which will be used in learning process and it shows that language learning strategies can be taught or learn since it is a skill [26]. Nevertheless, a researcher points out that language learning strategies is "the conscious or semi-conscious thoughts and behaviors used by learners with the explicit goal of improving their knowledge and understanding of a target language" (p. 280) [27]. It involves both cognitive and behavior in completing the task given. Oxford (1990a) defines language learning strategies by including the cognitive, emotional and social perspectives to assist learners in learning language. Generally, a researcher simplifies that learning strategies are the steps or action that learners take to deal with the language task given to them [28]. In brief, it can be said that language learning strategies are the steps or actions taken by learners, regardless of their consciousness in selecting the method, to complete the language task given to them. In other words, students are not aware the methods employed as long as the objectives of the tasks are achieved.

\subsection{Language Learning Strategies Models}

There are various language learning strategies models and one of them is Bialystok Model $[29,30]$. This model includes the component of cognition and there are four categories which are inferencing, monitoring, formal practicing and functional practicing [31]. Based on Bialystok's model, language learning strategies are used by the learners at all times whether they realize them as strategy or not and this topic is popular among researchers worldwide such as in the United States of America, Canada, South America and Asia, including Malaysia [32].

The theory of Second Language Learning by Bialystok consists of elements of learning strategies which knowledge is categorized as implicit linguistic, explicit linguistic and other knowledge. With regard to stages of second language learning, the Bialystok divided into three levels which are input, knowledge and output. A researcher defines explicit as knowledge about language, while implicit is knowledge about language which is spontaneously used and allows learners to use the language but may not be able to explain on the rules behind it [33]. Bialystok categorized language learning strategies into four types of strategies which are formal practicing, functional practicing, monitoring practicing and inferencing practicing. She defines formal practicing as knowledge gain on language system such as syntax, morphology and phonology through practicing language rules; functional practicing refers to use of language for communication, while monitoring refers to checking on the correct usage of language rules, and inferencing refers to guessing on meaning based on context.

There are many other theories related to language learning strategies which divided language learning strategies into three categories which are metacognitive strategies, cognitive strategies and socioaffective strategies $[34,35]$. Researchers keep investigating the topic on language learning established a model of language learning strategies which consists of two main categories namely direct and indirect strategies. Each category consists of three strategies and in total there are six strategies. In addition, a researcher proposed a new theory on language learning strategies with five main steps namely (1) management and planning strategies, (2) cognitive strategies, (3) communicativeexperiential strategies, (4) interpersonal strategies, and (5) affective strategies.

Even though there are numerous models or theories on language learning strategies, numerous researchers refer to Oxford's language learning strategies model. Oxford has compared the models of language learning strategies from the previous researchers to show the differences and classification from each one (Table 2.1). A researcher summarizes the type of language learning theory into five categories which are (1) research of good language learners, (2) psychological functions, (3) linguistic background, (4) language skills, and (5) distinction of learning styles or types of learners. In details, theory of language learning strategies introduced by Rubin in 1975 has fulfilled the first category, while theory by a researcher in 1990 fits into the second category which is related to psychological functions.

For the third category, the theory established by a researcher is related to linguistic background, and theory introduced by Cohen in 1991, suits the fourth category which is based on language skills. As for the fifth category, no specific theory of language learning strategies fit into that. Thus, it shows that the study of personality traits and its relationship towards language learning strategies is necessary as the fifth category has yet to be comprehensively understood.

Oxford's (1990a) language learning strategies model is the most consistent theory to assess language learning strategies among learners [36]. This model has categorized language learning strategies into two categories, namely direct and indirect learning strategies. Direct learning strategies inclusive of memorizing, cognitive and compensation strategies while, indirect strategies consist of metacognitive, affective and social. Metacognitive strategies are all about planning and thinking in how to execute certain learning situation. Cognitive is about action the learners take in learning situation such as note-taking, refer to other sources of information and social strategies involve interaction with others. Some learners prefer to communicate with the native speaker of the language to acquire the pronunciation of the words like the native speakers.

Oxford's Taxonomy divided language learning strategies into two main parts which are indirect strategies and direct strategies [37]. Both strategies are fairly important. The direct strategies have direct impact to language learning and the strategies are memory, cognitive and compensation. On the other hand, indirect strategies do not have direct relationship to language use, but they enhance language learning. The indirect strategies are metacognitive, affective and social strategies. In each six main strategies, there are 19 secondary strategies which followed by 62 specific strategies. The detail of the Oxford's Strategies Classification System is shown in Figure 2.1 and Figure 2.2 on the following page. Direct language learning strategy consists of three strategies namely memory, cognitive and compensation strategies. In details, memory strategies are divided into four sub-groups of strategies which are creating mental linkages, implying images, reviewing well and employing actions. Each component in memory strategy is accompanied with other specific strategies between one to four strategies. For example, for learners who prefer to create mental linkages, they may employ grouping, associate or elaborate or place new words according to context.

Second direct learning strategy is cognitive strategy which involves thinking process. This strategy consists of strategies such as practicing by repeating the new vocabulary they learned, practice sound of words formally and writing systems, recognize and use formula and pattern recombining and practice naturalistically. A researcher mentioned that cognitive strategies tend to manipulate learning materials directly in translation, note taking, summarizing, transferring and highlighting [38].

As for the third direct leaning strategy is compensation strategy which encompasses two strategies which are guessing intelligently and 
overcoming limitations in speaking and writing. Guessing intelligently allows learners to use linguistic clues and also using other clues. Meanwhile, if learners decided to employ the strategy by overcoming limitations in speaking and writing, they may speak in their first language, get help, use mime or gesture, avoid communication partially or totally, select certain topic to talk about, adjust or approximate the message, coining the words or use synonym.

Each strategy is accompanied by three other strategies. The first indirect strategy is metacognitive strategy which consists of centering of learning, arranging and planning learning and evaluate learning. For someone who prefers to use metacognitive strategy, they will arrange and plan their learning by finding about language learning, organize the learning, setting up goals and objectives for their learning, identify the purpose of language task given, make plan for the language task given and proactive find opportunity to practice the language. While for evaluating learning, learners may do self-monitoring and evaluate themselves.

Second indirect strategy is affective strategies which consist of lowering the anxiety, encouraging oneself, and taking emotional temperature. If students prefer to lower down their anxiety, they may use progressive relaxation, deep breathing or meditation. They may also use music to reduce their nervousness and laughing is also a strategy to employ to make them relax. Another sub-group of affective strategy is encouraging oneself. Students who prefer to prefer this strategy may make positive statements, taking risk wisely and reward themselves for the achievement that they made. Apart of that, students can also be alert on their emotional temperature by checking on your body, use checklist, write a language learning diary and discuss their feelings with someone.

The third sub-group of indirect learning strategies is social strategies. The strategies are asking questions, cooperating with others and empathizing with others. Asking for clarifications or verifications and asking for corrections are the sub-strategies for asking questions. As for cooperating with others, students may cooperate with others or with proficient language users of the language. The last sub-strategy is empathizing with others which students may develop cultural understanding and become aware of other people's thoughts and feelings. Social strategies enable learners to communicate with others including native speakers. The features clearly show that language learning strategies involve cognitive and also behavior action in completing the task given.

\subsection{Findings from Previous Studies}

Among the most popular strategies employed by second language learners are metacognitive, cognitive and social strategies, while another researcher found the high frequency used of compensation, cognitive and metacognitive among 110 second language learners of Thai university students [39]. With a slight different in finding, a previous researcher found that compensation was the most frequently used and followed by social, cognitive, metacognitive, memory and affective [40]. As for the tertiary and secondary ESL students in China, they used compensation strategies the most and in another study among 175 ESL students from China, it was discovered that the learners employed metacognitive and compensation strategies the most $[41,42]$. Compensation strategies was the most frequent used among 335 college students in Taiwan, the same finding was discovered [43].

In a nutshell, a scholar has interestingly concluded that learning strategies: is either behavior which is observable or mental which cannot be observed; could be general approaches or specific actions or techniques applied to learn Target Language where the learners are aware on which approach or techniques to choose, even though there are situations which are considered under subconscious [44]. Finding from a study among 42 form four students at government school in Penang, Malaysia found that the most frequent strategies employed are metacognitive, cognitive, affective, social, and compensation [45]. This result seems to have similar finding to study by a previous researcher. In a study which involved 194 university students of English as Foreign Language (EFL) in Iran prefer to use cognitive strategy, followed by metacognitive strategies [46].

Finding from a study among 42 form four students at government school in Penang, Malaysia found that the most frequent strategies employed are metacognitive, cognitive, affective, social, and compensation. This result seems to have similar finding to study by another researcher. A study found different findings in their study which involved 200 diploma students of UiTM Pahang at the range of 18 to 20 years old [47]. The respondents preferred to employ compensation the most followed by metacognitive strategies, social, cognitive, affective and memory strategies. Another study conducted in Penang by a researcher showed that metacognitive strategies were still the most highly employed by secondary school students. Nevertheless, a different finding was discovered among the 79 TESL students of University Malaya [48]. The students preferred to employ social learning strategies the most as compared to other learning strategies. Metacognitive strategy was their second most preferred learning strategies followed by cognitive strategies, compensation, affective and memory strategies. This is dissimilar with other studies involving university students in Malaysia. One possible reason could be due to their program of study which is TESL. Thus, it shows that there is a possibility that students of engineering technology might produce a different result as compared to students from other field of studies.

The findings from numerous studies worldwide produced various preference of learning strategies. There is no definite learning strategy as it could be influenced by various factors such as the culture, the trend on learning, the policy of the country which is different one from the other and the learner's personality or background.

\section{OBJECTIVE}

The objective of this research is to identify the most preferred language learning strategies employed by the learners of engineering technology.

\section{METHODOLOGY}

The study focuses on the students of Engineering Technology at one of private higher learning institutes in Johor Bahru which is Universiti Kuala Lumpur - Malaysian Institute of Industrial Technology (UniKL MITEC). For this study, it involved students from the three degree programs which are Bachelor of Engineering Technology (BET) in Quality Engineering, BET in Instrumentation and Control Engineering (BICE), and BET in Facility and Maintenance Engineering (BFaME). The respondents were from semester II and semester III because they were still enrolling in English subjects. The total number of BET student from semester II is 47 , which is 32.2 percent from the total population of semester 1I and the number of semester III student is 99 students. Thus, the total number of students for these two semesters is 146 , which represents 49.5 percent from the total population of BET students at UniKL MITEC as of April 2016 For this study, questionnaire was employed and Strategy Inventory of Language Learning (SILL) version 7.0 by a researcher was used [49]. This is due to positive feedback such as SILL is the most comprehensive and widely used instrument and also the most influential instrument [50,51]. It has also been recognized as "the most comprehensive classification of learning strategies". It has also been proven to be the best among other classification system with adequate indices of reliability and validity. The questionnaire consists of two different sections, with Section A is respondents' demographic information such as program of study, current semester of study and MUET result. Section B is meant for language learning strategies

SILL includes six categories of strategies which are memory, cognitive, compensation, metacognitive, affective and social. These six categories are presented in 50 statements, accompanied with five choices. Each category of strategy consists of different number of statements. For direct learning strategies, memory strategy has nine statements which are from question 1 to question 9, cognitive strategy has 14 statements (question 10 to question 23), and compensation strategy has 6 statements only (question 24 to question 29). Likewise, the indirect strategies consist of three strategies and each strategy contains a slight difference of total number of statements. In details, metacognitive has 8 statements (question 30 to question 38), while affective strategy and social strategy each with 6 statements.

The pilot test was conducted to find out the reliability of the questionnaire for this study. Based on the finding, SILL is reliable to be used. Among the six types of learning strategies, metacognitive has shown the highest Cronbach's Alpha which is 0.84 with nine items). The least type of learning strategies with low Cronbach's Alpha is affective strategies with 
only 0.59 . However, there are only six items for this strategy and a researcher mentioned that these items are acceptable due to number of questions in each strategy [52].

The data obtained from the questionnaire was analyzed statistically by using SPSS. Descriptive analysis and inferential statistic were used to summarize the overall findings of this study. In addition, frequency and percentage for every item in the questionnaire were analyzed and discussed.

\section{RESULT}

Demographic data provides information of the respondents in terms of the variables of the study. For this study, demographic characteristics of respondents are obtained from section $\mathrm{A}$ of the questionnaire which include gender, program of study, and current semester of study. For this study, demographic findings were analyzed based on frequency and percentage. There were 146 respondents involved in the study which consist of students of Bachelor of Engineering Technology (BET) programs from semester II and semester III. Table 1 shows that there are 97 male respondents which is 66.4 percent and 49 female respondents which equivalent to 33.6 percent. This obviously shows that male students overpowered female students in BET programs with a difference of 32.8 percent. This pattern which male students outnumbered female students in engineering programs is quite common in UniKL and might be similar to other higher learning institutes offering engineering program or engineering technology program. This could be due to nature of engineering field which is more suitable to male and it is also known that engineering field is male dominated field.

Table 1: Respondents involved according to gender

\begin{tabular}{|c|c|}
\hline Male & $97 / 66.4 \%$ \\
\hline Female & $49 / 33.6 \%$ \\
\hline
\end{tabular}

Universiti Kuala Lumpur - MITEC offers three degree programs of engineering technology which are Quality Engineering, Instrumentation and Control Engineering, and Facilities and Maintenance Engineering. A total of 66 respondents are from BET Instrumentation and Control Engineering (BET ICE), and this makes them as the majority. It is followed by BET Facilities and Maintenance Engineering (BET FaME) with 41 respondents which equivalent to 28.1 percent and BET Quality
Engineering (BET QE) with total number of 39 respondents or 26.7 percent. BQE is the first program offered at UniKL MITEC since 2008, while ICE program and FaME program are new programs which started in 2013. Based on the number of students according to programs, BQE has the least number of students.

Table 2: Respondents according to BET programs

\begin{tabular}{|c|c|}
\hline Program & Frequency \& Percentage \\
\hline ICE & $66 / 45.2 \%$ \\
\hline QE & $39 / 26.7 \%$ \\
\hline FaME & $41 / 28.1 \%$ \\
\hline
\end{tabular}

In this study, current semester of respondents involved is also part of the demographic characteristic. The respondents involved in this study either they were in semester II or semester III. Majority of the respondents were from semester III which was 99 respondents or 67.8 percent, while 47 respondents were from semester II which was equivalent to 32.2 percent. Engineering technology students from semester II and semester III were chosen for this study because they have adapted to the environment of university. In order to analyse finding from SILL, frequency of usage of each item is divided into three levels which are low, medium and high This category is according to Mean of each item in SILL, which was introduced by Oxford (1990a) and it is known as scale of strategy. For low category the Mean is between 1.0 to 2.4, while medium range is between 2.5 to 3.4, and high Mean is between the range of 3.5 to 5.0 .
SILL was employed to assess respondents' preferred language learning strategies. Based on the analysis, it was found that the overall Mean for SILL is at medium range $(\mathrm{M}=3.34, \mathrm{SD}=.471)$. Based on the findings, it was found that most of the items or 68 percent of them (34 items) are medium usage of language learning strategies. It is followed by high usage of strategies with 30 percent (15 items) and low usage of strategies with only 2 percent (1 item). Based on Mean from the questionnaire, most of engineering technology students used learning strategies moderately. This portrays that some of them rely on the teaching and learning activities provided by lecturers. However, 36 percent of them employ strategies that they prefer in language learning. It means that the teaching and learning activities in classroom may not enable them to acquire the language faster. They believe that their strategies are better to suit their learning.

Table 3: Language Learning Strategies - Means and Standard Deviations

\begin{tabular}{|c|c|c|}
\hline Strategy & M & SD \\
\hline Memory strategy & 3.16 & .95 \\
\hline Cognitive strategy & 3.47 & .97 \\
\hline Compensation strategy & 3.41 & .87 \\
\hline Metacognitive strategy & 3.49 & 1.04 \\
\hline Affective strategy & 3.09 & .98 \\
\hline Social strategy & 3.29 & \\
\hline
\end{tabular}

In details, most of the respondents preferred metacognitive strategies (M $=3.49, \mathrm{SD}=.87)$, followed by cognitive strategies $(\mathrm{M}=3.47, \mathrm{SD}=.94)$, compensation strategies $(\mathrm{M}=3.41, \mathrm{SD}=.97)$, while the least preferred strategies are affective strategies $(\mathrm{M}=3.09, \mathrm{SD}=1.04)$. Cognitive and compensation strategies are both direct strategies of language learning. All means according to six strategies are at the medium level, while in 
average, the Mean for language learning strategies is also in a range of medium level of usage. Table 3exhibits the details of Means and Standard Deviations for each strategy.

Metacognitive is the most preferred learning strategies among the respondents of this study and this has shown a slight different with finding from previous study which mentioned that Asian students prefer memorizing strategies [53]. Based on this study, learners of Engineering Technology prefer to plan their learning and re-evaluate their learning whether the strategies employed are directing them to their objectives. Furthermore, with the technologies and easy access of information, students are no longer think that memorizing strategies as vital strategies. This has been portrayed based on mean of language learning strategies for memory strategies are ranked as the fifth preferred strategies over six strategies. Nevertheless, students still also to use direct learning strategies since the second and third highest means are cognitive and compensation strategies. This can be inferred that learners still employ direct strategies apart of their most preferred indirect learning strategies. It can be inferred that the respondents still practice, receiving and sending messages, analyzing and provide reasons, and they also employ the strategies like guessing based on context and using gestures.

As to compare with previous studies, students from secondary and higher learning institute in China preferred to employ compensation strategies the most, as for learners in Japan, they tend to employ affective strategies the most [54,55]. In another study which involved university students which mostly are Chinese learning Japanese and French as foreign language. This study found that these learners preferred to use social learning strategies, and this is also supported by other study which discovered the same preferred strategies employed by learners in Taiwan and China [56,57]. Thus, to compare with the finding from this current study, there are differences as the students of engineering technology prefer to use metacognitive the most unlike the students from different countries which frequently use other strategies such as social and affective strategies. This could be due to difference culture, background, and the country itself. Even though Japan, Korea and China are located in the continent of Asia, the native language of all these countries are different.

\section{DISCUSSION}

Based on this finding, memory strategy is least preferred by the students of engineering technology. Nevertheless, among the strategies in memory learning strategies, they highly employ making mental picture when they try to remember new words in English (item 4). As for other items in memory Strategies, the learners used it moderately. This has shown that not all Asian students strongly prefer to employ Memory strategies in learning language as compared to finding by a researcher, and it is also in contrast to another researcher who found out that Asian students memorized words from book because the respondents believed that knowledge can be gained from book [58]. However, nowadays with the Internet and other technology, memorizing is no longer the most significant strategies. That could be the reason why memory learning strategy is ranked as learners' fifth preferred learning strategies in this study. Engineering technology students of UniKL MITEC might in favour of using technology as information is accessible at any time. They only employ memory learning strategies when needed such as for examination purposes. Based on the finding on Mean and Standard Deviation, it was found that engineering students of UniKL MITEC prefer to make mental picture on the word they might use in the situations, as they felt that strategy is easy as compared to others. They also relate to what they already know with new things that they learned. Learners usually try the techniques that suit their preference but if that did not produce the target result, they will have to find other learning strategies.

According to the finding, the students of engineering technology prefer to employ strategy which first does not involve other individual. Their first preference in cognitive learning strategies is watching television on English spoken programs. This generation takes advantage of the existing technology available which is television. Television nowadays has many English spoken programs either local or foreign. Apart of that, they also prefer to practice the sound of English as to have certain accent make them feel good. The students believe that English spoken program on television will be able to help them to practice their pronunciation.
Furthermore, there are other sources on Internet such as YouTube which will definitely supply various accents of English. Apart of that, with the existing of Internet and technology, online application such as dictionary is accessible easily. Thus, television might represent technology and Internet as to suit the generation nowadays.

Among compensation strategies, the students of engineering technology prefer to guess the meaning of unfamiliar words in English. Guessing is one of the best strategies to learn vocabulary which students may guess the meaning of unfamiliar words based on context. Furthermore, having to refer to dictionary every time they find unfamiliar words will interrupt their reading enjoyment and students do not bring dictionary wherever they go. Even though nowadays dictionary application for mobile phone is available, not many students install the application. It shows that students would prefer to guess the meaning according to context rather than to flip a dictionary. The next preferred strategy is trying to guess the words that someone will say in English. They also prefer to use phrase or word to replace the exact word that they could not remember or do not know. In other word, they are in favour to explain or describe the words that they could not think of.

Compensation is the third most frequent strategies used by the students of engineering technology and this describes the strategies used such as guessing from context, asking the speaker to slow down the pace when speaking, pay attention to the speaker. These are some of the characteristics of Asian learners. Apart of that, it also shows that the engineering students of UniKL MITEC guess the words that they do not understand the most, as this is shown in the mean for item 24. They are also in favour to use gestures for words that they cannot think of. In other words, learners of engineering technology use these strategies more frequently in learning English as compared to affective and social strategies.

In addition, good language learner should be willing to employ strategies such as guessing meaning from context which is one of the strategies in compensation. Comparing with the language proficiency of respondents of this study, which most of the learners are at moderate level and compensation ranked as the third highest most frequently used by learners portrays the type of learners. This means that since majority of learners are not considered as good language users, they do not employ compensation technology as their first preferred learning strategies. Respondents of this study used metacognitive strategies the most as compared to other students such as Chen (2005) which the students in China preferred compensation strategies the most.

Based on the frequency and percentage in Table 4.26 the engineering technology students from UniKL usually pay attention when someone is speaking English (item 32). It shows that by paying attention, they also learn the pronunciation and obtain new vocabulary. They seem to believe that focusing on someone like the lecturers teaching in class is their preferred strategies especially to students who have high usage of metacognitive strategies. Another strategy is the students noticed the mistake that they make in English and they use the information to improve themselves. Metacognitive strategy is the most preferred strategies by the students of engineering technology. This means that they realized that they want to be good language user as that will be beneficial to them. Besides that, students of engineering technology also try to find out how they can be better learner of English (item 35). Some of them ask the lecturers on the steps to be taken for them to improve their language skills while some of them might go activity they like but at the same time allow them to learn English.

This finding is in agreement to a study by a group of researchers which the respondents of Chinese university student preferred to employ metacognitive strategies the most [59]. However, in another study which involved Chinese students and also three other races as Japanese, Korean and others, Chinese students prefer to use social strategies as compared to Japanese, Korean and other races with the highest preference of metacognitive [60]. The similarity is both are non-native speaker of English. This portrays that non-native speakers prefer to use strategies such as concentrate to someone who is speaking, finding out how to be better language learner and also take note of mistake done in using the language. Furthermore, Indian college students also prefer to employ metacognitive strategies as [61]. Based on previous studies, it can be said that learners of non-native speaker prefer to use metacognitive strategies 
as these strategies allow them to find ways to use English by looking for people that they can converse in English so that they can practice and improve their language proficiency.

The engineering technology students sometimes use affective strategies since the higher scores are located in Likert scale 3. Among the most preferred strategy in affective learning strategies is they notice when they are nervous or tense when learning or using English. It displays that the students are alert on many elements which relate to English such as grammar, and pronunciation. This could be the explanation for being nervous when using English, unlike certain students who do not focus so much on grammar and pronunciation, instead more towards the message or content. Another affective strategy employed by engineering technology students was they reward themselves whenever they performed well in English. That could be the self-motivation to encourage themselves to be better language user. Item 43 (I write down my feelings in a language learning diary) shows the highest percentage of students who never employed this strategy. It exhibits that the engineering technology students did not prefer to write their feelings in diary and this could be due to the majority of students are male.

Affective strategies are mostly considered the least strategy employed based on previous studies (Oxford, 1990a) and finding from this study is in agreement to that as it is ranked as the least preferred strategies. It exhibits that engineering technology students employed affective strategies the least in language learning. Among the strategies in affective group of strategies are lowering learner anxiety and give selfencouragement. This finding is in agreement to a researcher which affective learning strategy is the least preferred by monolingual Korean university students [62]. As for local context comparison, another researcher discovered that Malaysian secondary school students prefer to use affective strategies the most, while the least preferred strategy is compensation strategies [63].

This same finding is in agreement to the study which involved 50 Chinese distance learners at Shantou Radio and Television University in China [64]. It was found that students from the first year, second year and those who have graduated preferred to use affective strategies the most, while the third year students preferred to employ cognitive strategies. Thus, in average the most frequent used of strategies among the distance learners is affective strategy. The differences between the ranked of affective strategies in this study and other studies could be due to certain factors. The students of engineering technology of this study have access to Internet as compared to secondary school students and for distance learners in China they might have insecure feeling in which they rarely have contacted with other learners and also the teachers.

Social learning strategy is listed as the fifth preferred strategy among the learners of engineering technology with mean 3.29 which can be considered as medium level of usage. In order to compare with local context which is the secondary students, they ranked social strategies as the third most preferred strategies. Based on these results, the setting which is in school and the respondents which are still young could be the rationale behind the differences. At school, students are treated differently than the students at university. When the students are at university, they adapt to the system and environment in which their language learning strategies might change too. In another study conducted, first year TESL students from local university ranked social strategies as the second most preferred strategies. It is in contrast to the current study which social strategies are placed at number five and different field of study could be the reason for the differences. Nevertheless, on the most preferred learning strategies, metacognitive strategies are still the most preferred by both groups of learners regardless of Engineering Technology or TESL.

\section{CONCLUSION}

As conclusion, majority of the students of engineering technology involved in this study preferred to employ metacognitive language learning strategies followed by cognitive language learning strategies, while the least preferred strategy is social learning strategy. With this information, lecturers should be able to plan teaching and learning activities which consist of more metacognitive and also cognitive elements. These findings contribute awareness to lecturers and program or subject developer to take into consideration of this information because teaching and learning activities should help students to improve their language performance. With the findings, lecturers and curriculum designer or subject developer should take into consideration on students' preferred learning strategies when planning for the content. However, this finding does not provide ultimate solution to the issue of poor language performance among the students. This is due to the dynamic of learning strategies itself which there are other factors to be considered. More studies which require deeper understanding on language learning strategies should be conducted as to provide a very comprehensive understanding on learners of engineering technology.

\section{REFERENCES}

[1] Teh, S.N. 2009. Learn Mandarin to connect with China: MM Lee Business Times 18 March 2009. Retrieved from http://app.mfa.gov.sg/pr/read_content.asp?View,12370.

[2] Yamat, H., Umar, N.F.M., Mahmood, M.I. 2014. Upholding the Malay Language and Strengthening the English Language Policy: An Education Reform. International Education Studies, 7(13), 197-205.

[3] Saharuddin N., Hussin, S. 2014. English Language Needs of Industrial Trainees in Chemical Engineering Industry: A Case of UniKL MICET. LSP International, 1, June 2014, 25-33.

[4] Wan Salim, W.I., Subramaniam, V., Termizi, A.A. 2017. Foreign Language Anxiety (FLA) in English Language Classroom. International Journal of Languages, Literature and Linguistics, 3(1), 5-12.

[5] Sahragard, R., Baharloo, A., Soozandehfar, M.A. 2011. A closer look at the relationship between academic achievement and language proficiency among Iranian EFL students. Theory and Practice in Language Studies, 1(12), 1740-1748.

[6] Maleki, A., Zangani, E. 2007. A survey on the relationship between English language proficiency and the academic achievement of Iranian EFL students. Asian EFL Journal, 9(1), 86-96.

[7] Butler, F.A., Castellon-Wellington, M. 2000. Students' concurrent performance on tests of English language proficiency and academic achievement. In, the validitiy of administrating large-scale content assessments to English language learners: An investigation from three perspectives. National Center for Research on Evaluation, Standards, and student testing. University of California, Los Angeles.

[8] Kato, S. 2009. The Relationship of Language Learning Strategies and Personality on English Proficiency in Japanese University Students. The Journal of ASIA TEFL, 6(1), 141-162, Spring 2009.

[9] Dornyei, Z. 2009. Individual Differences: Interplay of Learner. Language Learning, 59(December), 230-248.

[10] Nunan, D. 1999. Second Lnguage Teaching and Learning. Heinle. Boston, MA.

[11] Rubin, J. 1975. What the "good language learner" can teach us. TESOL Quarterly, 9(1), 41-45.

[12] Stern, H.H. 1975. What can we learn from the good language learner? Canadian: Modern Language Review, 31, 304-318.

[13] O'Malley, J.M., Chamot, A.U. 1987. The Cognitive Academic Language Learning Approach: A Bridge to the Mainstream. TESOL Quarterly, 21(2), 227 - 249.

[14] Oxford, R.L. 1990a. Language Learning Strategies: What Every Teacher Should Know,New York: Newbury House.

[15] Wenden, A. 1991. Learning Strategies in learning. Prentice-Hall International.

[16] Cohen, A.D. 1998. Strategies in learning and using a second language, Harlow, England: Longman. 
[17] Chamot, A.U. 2001. The role of learning strategies in second language acquisition. In Learner contributions to language learning: New directions in research, 25-43.

[18] Nambiar, R. 2009. Learning Strategy Research - Where are we now? The Reading Matrix, 9(2), 132-149.

[19] Vlckova, K., Berger, J., Volkle, M. 2013. Classification theories of foreign language learning strategies: an exploratory analysis. Studia paedagogica, 18(4), 93-113. doi:10.5817/SP2013-4-6.

[20] Rigney, J. 1978. Learning strategies: A theoretical perspective. In O'Neil, H.F. Jr. (Ed.) Learning Strategies: New York: Academic Press.

[21] Rubin, J. 1987. Learner strategies: Theoretical assumptions, research history and typology. In A.L. Wenden \& J. Rubin (Eds.), Learner strategies in language learning, 15-30. Englewood Cliffs, NJ: Prentice Hall.

[22] O'Malley, J.M., Chamot, A.U. 1990. Learning strategies in second language acquisition. Cambridge: Cambridge University Press.

[23] Chamot, A.U. (2005). Language learning strategies instruction: current issues and research. Annual Review of Applied Linguistics, 25, 112-130.

[24] Scarcella, R., Oxford, R. 1992. The Tapestry of Language Learning: The Individual in the Communicative Classroom. Boston: Heinle \& Heinle.

[25] Embi, MA. 2000. Language Learning Strategies: A Malaysian Context. Penerbit UKM: Bangi.

[26] Williams, M., Burden, R.L. 1997. Psychology for language teachers: A social constructive approach. Cambridge: Cambridge University Press.

[27] Cohen, A.D. 2003. The learner's side of foreign language learning: where do styles, strategies, and tasks meet? IRAL 41(4), 279-291.

[28] Oxford, R.L. 2003. Language learning styles and strategies: concepts and relationships.IRAL 41(4), 271-278.

[29] Ellis, R. 1990. Instructed Second Language Acquisition. Oxford: Basil Blackwell.

[30] Stern, H.H. 1992. Issues and options in language teaching. Oxford University Press.

[31] Bialystok, E. 1978. A theoretical model of second language learning. Language learning, 28(1), 69-83.

[32] Mohamad, A., Md Husain, F., Karia, N. 2014. A learning strategy profile of undergraduate university students in a public tertiary educational institution. International Journal of Arts and Commerce, 3(8), 172-184.

[33] Brown, H.D. 2007. Principles of Language Learning and Teaching. $5^{\text {th }}$ Ed. Pearson ESL: Longman.

[34] O'Malley, J.M., Chamot, A.U., Stwener-Manzanares, G.L.O.R.I.A., Russo, R.P., Kupper, L. 1985a. Learning strategy applications with students of English as a second language. TESOL quarterly, 19(3), 557-584.

[35] O'Malley, J.M., Chamot, A.U., Srewner-Mazanares, G., Kupper, L., Russo, R.P. 1985b. Learning strategies used by beginning and intermediate ESL students. Language Learning, 35, 21-46.

[36] Hsiao, T.Y., Oxford, R.L. 2002. Comparing theories of language learning strategies: A confirmatory factor analysis. The Modern Language Journal, 86(3), 368-383.

[37] Ehrman, M.E., Oxford, R. 1990. Adult Language Learning Strategies and Strategies in an Intensive Training Setting. The Modern Language Journal, 74, 311-327.
[38] Embi, MA., Mohd Amin MZ. 2010. Strategiesfor Successful English Language Learning. Karisma Publications Sdn Bhd: Shah Alam.

[39] Mullins, P.Y. 1992. Successful English language learning strategies of students enrolled at the Faculty of Arts, Chulalongkorn University Bangkok, Thailand.

[40] Ehrman, M.E., Oxford, R.L. 1995. Cognition plus: correlates of language learning success. Modern Language Journal, 79(1), 67-89.

[41] Bedell, D.A., Oxford, R.L. 1996. Cross-cultural comparisons of language learning strategies in the People's Republic of China and other countries. Language learning strategies around the world: Cross-cultural perspectives, 47-60.

[42] Goh, C., Foong, K.P. 1997. Chinese ESL students' learning strategies: A look at frequency, and gender. Hong Kong Journal of Applied Lingusitic, 2(1), 39-53.

[43] Ku, P.Y.N. 1997. Predictors of strategy choice by EFL students in Taiwan. Paper presented at RELC Seminar, Singapore, April 1997.

[44] Liang, T. 2009. Language learning strategeis - The theoretical framework and some suggestions for learner training practice. English Language Teaching, 2(4), 199-206.

[45] Rajamoney, S.S. 2008. A study on the use of language learning strategies after strategy training among from four ESL students: A case study (LB1631. S558 2008f rb) Doctoral dissertation, Universiti Sains Malaysia.

[46] Safdarian, Z., Ghyasi, M., Farsani, M.A. 2014. How Reading Strategy Use And Personality Types Are Related?The Reading Matrix, Volume 14, Number 1, April 2014, 121 - 134.

[47] Badaruddin, Z., Rashid Ali, F.D. 2010. Language Learning Strategies: Preference Of Malaysian University Students. Academia, retrieved on 20 January 2019 from https://www.academia.edu/7025987/language_learning_strategies_pref erence_of_malaysian_university_students

[48] Chew, F.P., Tian, Z. 2012. Language Learning Strategies of PreService TESL Teacher at University of Malaya. International Journal of Research in Economics \& Social Sciences, 2(2), 64-85.

[49] Ellis, R. 1994. The study of Second Language Acquisition. Oxford: Oxford University Press.

[50] Shakarami, A., Mardziha, H.A. 2002. Language learning strategies and styles among Iranian engineering and political science graduate students studying abroad. Educational Research and Reviews, 5(2), 35-45.

[51] Rivera-Mills, S.V., Plonsky, L. 2007. Empowering students with language learning strategies: A critical review of current issues. Foreign Language Annals, 40(3), 535-548.

[52] Ramayah, T., Lee, J.W.C., In, J.B.C. 2011. Network collaboration and performance in the tourism sector. Service Business, 5(4), 411.

[53] Politzer, R., McGroarty, M. 1985. An exploration study of learning behaviours and their relationship to gains in linguistic and communicative competence. TESOL Quarterly, 19, 103-124.

[54] Bedell, D. 1993. Cross-cultural variation in choice of language learning strategies: A mainland Chinese investigation with comparison to previous studies. Unpublished master's thesis, University of Alabama, Tuscaloosa, AL.

[55] Grainger, P.R. 1997. Language-learning strategies for learners of Japanese: Investigating ethnicity. Foreign Language Annals, 30(3), 378385.

[56] Wharton, G. 2000. Language learning strategy use of bilingual foreign language learners in Singapore. Language Learning, 50(2), 203243. 
[57] Yang, N.D. 1992. Second Language learners' beliefs about language learning and their use of learning strategies: A study of college students of English in Taiwan. Unpublished doctoral dissertation, The University of Texas at Austin.

[58] Scarcella, R.C. 1990. Teaching language minority students in multicultural classroom. Englewood Cliffs, NJ: Prentice Hall.

[59] Nisbet, D.L., Tindall, E.R., Arroyo, A.A. 2005. Language Learning Strategies and English Proficiency of Chinese University Students. Foreign Language Annals, 38(1), 100-107.

[60] Hong-nam, K., Leavell, A.G. 2006. Language learning strategy use of ESL students inan intensive English learning context. System, 34(2006), 399-415

[61] Sheorey, R. (1999). An examination of language learning strategies use in the setting of an indigenized variety of English. System, 27, 173-190.

[62] Hong-Nam, K., Leavell, A.G. 2007. A Comparative Study of Language Learning Strategy Use in an EFL Context: Monolingual Korean and Bilingual Korean-Chinese University Students. Asia Pacific Education Review, 8(1), 71-88.
[63] Abdul Razak, N.Z., Babikkoi, M.A. 2014. English Language Learning Strategies of Malaysian Secondary School Students: Implication for InterCultural Communication. Sociology Mind, 4, 206-212.

[64] Xiao, J., Hurd, S. 2007. Language Learning Strategies in Distance English Learning: A Study of Learners at Shantou Radio and Television University, China. The Journey of Asia TEFL, 4(2), 141-164.

[65] Chen, L. 2005. The relationship among perceptual style preferences, language learning strategies, and personality types among Taiwan senior high school EFL students. Ph.D. Thesis, Indiana State University.

[66] Oxford, R.L. 1989. Use of language learning strategies: A synthesis of studies with implications for strategy training. System, 17(2), 235-247.

[67] Pallant, J. 2016. SPSS Survival Manual, England: McGraw-Hill Education.

[68] Sy, B.M. 1994. Sex differences and language learning strategies. Papers from the Eleventh Conference on English Teaching and Learning in the Republic of China. Taipei, Taiwan: The Crane Publishing Co, 19-41

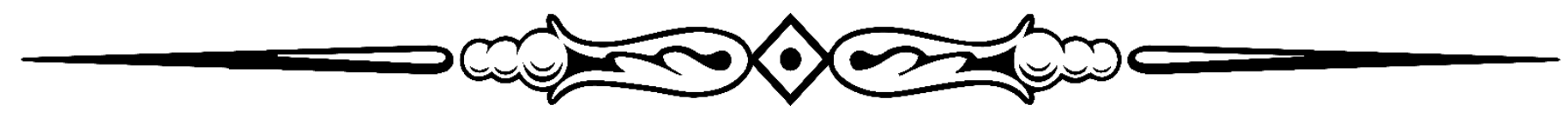

